\title{
Protecting Postextubation Respiratory Failure and Reintubation by High-Flow Nasal Cannula Compared to Low-Flow Oxygen System: Single Center Retrospective Study and Literature Review
}

\author{
Minhyeok Lee ${ }^{1,2}$, Ji Hye Kim', In Beom Jeong', Ji Woong Son', Moon Jun Na', Sun Jung Kwon' \\ ${ }^{1}$ Division of Respiratory and Critical Care Medicine, Department of Internal Medicine, Konyang University Hospital, Daejeon; ${ }^{2}$ The 2nd Infantry Division of \\ Republic of Korea Army, Yanggu, Korea
}

Background: Use of a high-flow nasal cannula (HFNC) reduced postextubation respiratory failure (PERF) and reintubation rate compared to use of a low-flow oxygen system (LFOS) in low-risk patients. However, no obvious conclusion was reached for high-risk patients. Here, we sought to present the current status of HFNC use as adjunctive oxygen therapy in a clinical setting and to elucidate the nature of the protective effect following extubation.

Methods: The medical records of 855 patients who were admitted to the intensive care unit of single university hospital during a period of 5.5 years were analyzed retrospectively, with only 118 patients ultimately included in the present research. The baseline characteristics of these patients and the occurrence of PERF and reintubation along with physiologic changes were analyzed.

Results: Eighty-four patients underwent HFNC, and the remaining 34 patients underwent conventional LFOS after extubation. Physicians preferred HFNC to LFOS in the face of highrisk features including old age, neurologic disease, moderate to severe chronic obstructive pulmonary disease, a long duration of mechanical ventilation, low baseline arterial partial pressure of oxygen to fraction of inspired oxygen ratio, and a high baseline alveolar-arterial oxygen difference. The reintubation rate at 72 hours after extubation was not different $(9.5 \%$ vs. $8.8 \% ; \mathrm{P}=1.000$ ). Hypoxic respiratory failure was slightly higher in the nonreintubation group than in the reintubation group ( $31.9 \%$ vs. $6.7 \% ; \mathrm{P}=0.058)$. Regarding physiologic effects, heart rate was only stabilized after 24 hours of extubation in the HFNC group.

Conclusions: No difference was found in the occurrence of PERF and reintubation between both groups. It is worth noting that similar PERF and reintubation ratios were shown in the HFNC group in those with certain exacerbating risk factors versus not. Caution is needed regarding delayed reintubation in the HFNC group.

Key Words: airway extubation; high-flow nasal cannula; postextubation respiratory failure

\section{INTRODUCTION}

Postextubation respiratory failure (PERF) and reintubation are related to ventilator-associated pneumonia, mortality rates, and a longer stay both in the intensive care unit (ICU) and hospi-

\section{Original Article}

Received: October 18, 2018

Revised: February 2, 2019

Accepted: February 21, 2019

Corresponding author

Sun Jung Kwon

Division of Respiratory and Critical

Care Medicine, Department

of Internal Medicine, Konyang

University Hospital, 158

Gwanjeodong-ro, Seo-gu, Daejeon

35365, Korea

Tel: +82-42-600-8820

Fax: +82-42-600-9100

E-mail: sjoongkwon@hanmail.net

Copyright (@) 2019 The Korean Society of Critical Care Medicine

This is an Open Access article distributed under the terms of Creative Attributions Non-Commercial License (http://

creativecommons.org/li-censes/by-nc/4.0/) which permits unrestricted noncommercial use, distribution, and reproduction in any medium, provided the original work is properly cited. 
tal in general [1]. Adjuvant oxygen therapy has commonly been used to prevent these undesirable events. The conventional low-flow oxygen system (LFOS) approach that includes a nasal cannula and facial mask has been used widely. However more recently, a high-flow oxygen system (HFOS) including noninvasive ventilation (NIV) and high-flow nasal cannula (HFNC) has been preferred due to its physiologic benefits [2-6].

NIV has been used as a substitute for LFOS in acute respiratory failure $[2,7]$. It has also recently been applied with adjuvant oxygen application after extubation and has shown lower PERF and reintubation rate than LFOS [2,7]. In terms of physiologic aspects, this device is helpful to reduce the arterial partial pressure of carbon dioxide $\left(\mathrm{PaCO}_{2}\right)$ and increases the arterial partial pressure of oxygen $\left(\mathrm{PaO}_{2}\right)$ relative to that of LFOS $[2,6,7]$. However, it cannot be universally used because of the inconvenient interface and its own associated complications (e.g., dyssynchrony, barotrauma, pneumonia) [8].

HFNC is a newly developed device that can supply heated and humidified gas at a relatively constant fraction of inspired oxygen $\left(\mathrm{FiO}_{2}, 0.21-1.0\right)$ and flow rate (up to $60 \mathrm{~L} / \mathrm{min}$ ) [9]. This device has also demonstrated more physiologic benefits than LFOS. For example, it can wash out $\mathrm{PaCO}_{2}$ in an anatomical dead space and create a positive nasopharyngeal pressure that, in theory, consequently prevents alveolar collapse and increases lung volume $[10,11]$. Also, contrary to the dry oxygen supply, heated and humidified gas improves mucociliary function [9]. In addition, in comparison with NIV, which requires a sealed interface, HFNC has a more comfortable nasal cannula capable of allowing expectoration of sputum, so it can be used widely among both general and critically ill patients $[5,6]$.

To ensure that these benefits are helpful after extubation, many studies have been conducted but have presented mixed results [4-6,12-16]. In low-risk patients, a large-scale study comparing HFNC with LFOS proved effective, but there was no obvious conclusion in the high-risk group.

Therefore, in this retrospective study, we tried to show the current status of HFNC use in the clinical setting and evaluate the efficacy of HFNC in PERF and reintubation in high-risk patients. Physiologic changes according to time were also analyzed to determine whether the benefit of HFNC plays a physiologic role in postextubation.

\section{MATERIALS AND METHODS}

\section{Study Design and Populations}

This was a retrospective study conducted in an ICU of a single

\section{KEY MESSAGES}

- In high-risk patients, no difference was found in occurrence of postextubation respiratory failure (PERF) and reintubation between the high-flow nasal cannula (HF$\mathrm{NC}$ ) and low-flow oxygen system groups.

- Physicians preferred applying HFNC in riskier patients. It is worth noting that similar PERF and reintubation ratios were shown in the HFNC patients with more risk factors versus less.

- When implementing HFNC in high-risk patients, caution is needed due to the possibility of delayed reintubation.

center at Konyang University Hospital, Daejeon, Korea. The medical records of 855 patients who were admitted to the ICU and received mechanical ventilator therapy between November 2011 and March 2017 were reviewed. Seven hundred thirty-six patients were ultimately removed due to the study exclusion criteria (Figure 1). Patients who had at least one highrisk factor (e.g., age older than 65 years, body mass index higher than $30 \mathrm{~kg} / \mathrm{m}^{2}$, Acute Physiologic and Chronic Health Evaluation (APACHE) II score greater than 12 points, duration of mechanical ventilation greater than 7 days, Charlson comorbidity index of 2 points or more, heart failure as a cause of intubation, moderate to severe chronic obstructive pulmonary disease (COPD), failure with first spontaneous breathing trial (SBT) were defined as high-risk patients for PERF and reintubation according to a previous study [6]. One patient who did not have any such risk factors was also excluded (Figure 1). Consequently, 118 patients were included in this study, 84 of whom had undergone HFNC, and the other 34 of whom had undergone conventional LFOS.

A physician evaluated the patient status each day and determined the possibility of extubation by awakening and a SBT according to the weaning protocol of the ICU of Konyang University Hospital. After and during the extubation, adjunctive $\mathrm{O}_{2}$ supply (HFNC or LFOS) was provided. HFNC was delivered by the Optiflow system or Airbo-2 (Fisher \& Paykel Healthcare, Auckland, New Zealand). The supplied $\mathrm{FiO}_{2}$ and gas flow were operated and controlled by a bedside physician according to the patient's conditions, respiratory effort, target oxygenation, and arterial blood gas analysis. After extubation, the patient's condition was evaluated in terms of respiratory discomfort, arterial blood gas, and vital signs. When PERF occurred, reintubation was determined by the bedside physician. This study was approved by the Institutional Review Board of Konyang University Hospital (IRB No. 2017-11-006). 


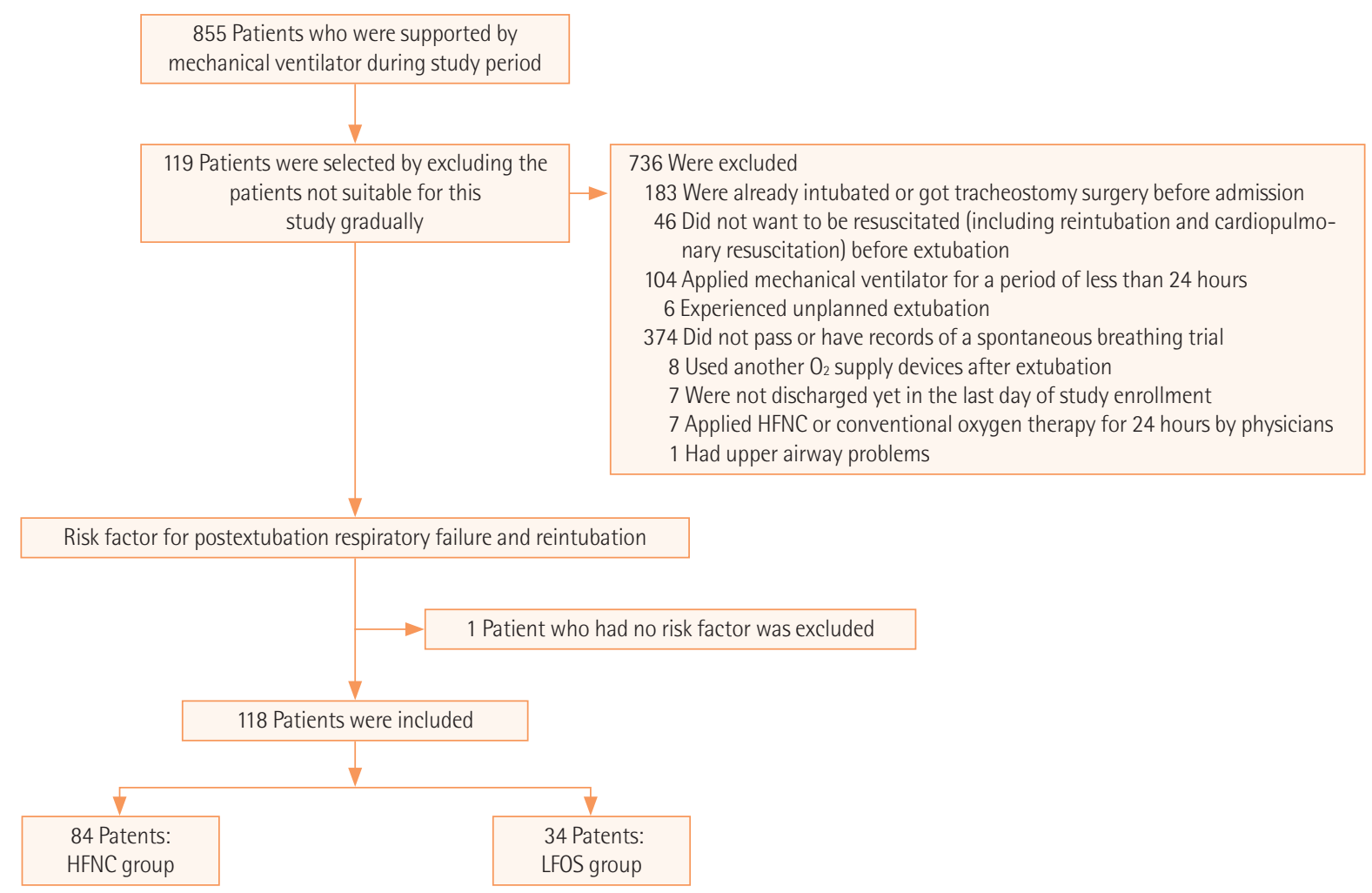

Figure 1. Study design and population. In 855 patients who experienced mechanical ventilator use during the analyzed periods, 737 who matched the exclusion criteria and/or who did not have risk factors were excluded. Finally, 118 patients were included and analyzed retrospectively. HFNC: high-flow nasal cannula; LFOS: low-flow oxygen system.

\section{Data Collection}

Data were collected from the medical records including the general characteristics of the patients, the cause of respiratory failure, arterial blood gas analysis findings, vital signs before intubation and after extubation, ventilator period, and interval to reintubation. PERF was defined according to three categories: hypercapnic respiratory failure $\left(\mathrm{pH}<7.35\right.$ and $\mathrm{PaCO}_{2}$ $>45 \mathrm{mmHg})$, hypoxic respiratory failure $\left(\mathrm{PaO}_{2}<60 \mathrm{mmHg}\right)$, and tachypneic respiratory failure (respiratory rate $>35$ breaths/ $\mathrm{min}$ ). Reintubation was also classified into three groups: early reintubation (reintubation in 72 hours after extubation), delayed reintubation (reintubation between 72 hours and 168 hours after extubation), and nonreintubation (no occurrence of reintubation up to 168 hours after extubation).

\section{Statistical Analysis}

Categorical and noncategorical variables are expressed as number (percentage) and median (25th-75th, interquartile range). Fisher exact test or the chi-square test was used to compare the categorical variables, and the Mann-Whitney U-test was used for comparisons of noncategorical variables. Changes in $\mathrm{PaO}_{2} / \mathrm{FiO}_{2}, \mathrm{PaCO}_{2}$, respiratory rate, and heart rate according to time were analyzed using the Friedman test. Post-hoc analysis of the Friedman test was conducted using the Wilcoxon rank-sum test when the Freidman test showed significance. A $P$-value less than 0.05 was considered statically significant. The IBM SPSS ver. 22.0 (IBM Corp., Armonk, NY, USA) was used for data analysis.

\section{RESULTS}

\section{Baseline Characteristics of the Enrolled Patients}

The baseline characteristics of 118 patients suitable for this study are presented in Table 1. The cause of invasive mechanical ventilation and the APACHE II score did not differ between the groups. However, there were differences in underlying disease and high-risk factors. Patients who had more baseline neurologic diseases ( $32.1 \%$ vs. $11.8 \%, \mathrm{P}=0.023)$, a long duration of mechanical ventilation before extubation (median, 120.3 vs. 81.93 hours; $\mathrm{P}=0.012$ ), and longer hospital stay before extubation (median, 7.5 vs. 4.5 days; $\mathrm{P}=0.005$ ) were more likely to be supported by HFNC. The HFNC group also showed a lower baseline $\mathrm{PaO}_{2} / \mathrm{FiO}_{2}$ versus the LFOS group (130.78 vs. 255.71 $\mathrm{mmHg}, \mathrm{P}=0.001$ ) and a higher baseline alveolar-arterial oxy- 
Table 1. Baseline characteristics of analyzed patients before intubation

\begin{tabular}{|c|c|c|c|}
\hline Characteristics & $\operatorname{HFNC}(n=84)$ & $\operatorname{LFOS}(n=34)$ & P-value \\
\hline Male sex & $60(71.4)$ & $20(58.8)$ & 0.184 \\
\hline Age (yr) & $73.0(66.0-80.0)$ & $71.00(55.75-81.25)$ & 0.454 \\
\hline Height (cm) & $163.5(158.0-170.0)$ & 155.50 (160.00-169.50) & 0.248 \\
\hline Body weight (kg) & $56.65(50.0-68.0)$ & $58.00(52.00-65.00)$ & 0.983 \\
\hline Body mass index (kg/m²) & $22.0(18.8-24.5)$ & $23.11(19.44-24.92)$ & 0.703 \\
\hline \multicolumn{4}{|l|}{ Underlying disease } \\
\hline Diabetes mellitus & $19(22.6)$ & $6(17.6)$ & 0.549 \\
\hline Hypertension & $31(36.9)$ & $12(35.3)$ & 0.869 \\
\hline Malignant disease & $10(11.9)$ & $4(11.8)$ & $1.000^{\mathrm{a}}$ \\
\hline Chronic respiratory disease & $47(56.0)$ & $15(44.1)$ & 0.244 \\
\hline Chronic heart disease & $22(26.2)$ & $7(20.6)$ & $0.522^{\mathrm{a}}$ \\
\hline Chronic liver disease & $1(1.2)$ & 0 & $1.000^{\mathrm{a}}$ \\
\hline Chronic renal disease & $11(13.1)$ & $3(8.8)$ & $0.755^{\mathrm{a}}$ \\
\hline Neurologic disease & $27(32.1)$ & $4(11.8)$ & 0.023 \\
\hline \multicolumn{4}{|l|}{ Cause of mechanical ventilation } \\
\hline Pneumonia & $45(53.6)$ & $19(55.9)$ & 0.819 \\
\hline Airway disease & $13(15.5)$ & $3(8.8)$ & 0.119 \\
\hline Hemoptysis & $3(3.6)$ & $1(2.9)$ & $1.000^{\mathrm{a}}$ \\
\hline Drug intoxication & $14(16.7)$ & $10(29.4)$ & 0.119 \\
\hline Post operation & $2(2.4)$ & 0 & $1.000^{\mathrm{a}}$ \\
\hline Heat failure & $3(3.6)$ & 0 & $0.556^{\mathrm{a}}$ \\
\hline Others & $4(4.8)$ & $1(2.9)$ & $1.000^{\mathrm{a}}$ \\
\hline \multicolumn{4}{|l|}{ Type of respiratory failure at intubation ${ }^{b}$} \\
\hline Tachypneic respiratory failure & $6(7.1)$ & $2(5.9)$ & $1.000^{\mathrm{a}}$ \\
\hline Hypercapnic respiratory failure & $38(45.2)$ & $12(35.3)$ & 0.322 \\
\hline Hypoxic respiratory failure & $23(27.4)$ & $6(17.6)$ & $0.266^{\mathrm{a}}$ \\
\hline Others ${ }^{c}$ & $22(26.2)$ & $14(41.2)$ & 0.109 \\
\hline \multicolumn{4}{|l|}{ Severity index } \\
\hline APACHE II score at ICU admission & $22.0(18.00-25.00)$ & $22.00(19.00-25.25)$ & 0.466 \\
\hline APACHE II score at extubation & $17.0(14.0-19.0)$ & $16.50(14.00-19.00)$ & 0.466 \\
\hline \multicolumn{4}{|c|}{ Vital sign and arterial blood gas before intubation } \\
\hline Heart rate & $100.00(85.00-120.00)$ & $107.50(85.75-121.00)$ & 0.861 \\
\hline Respiratory rate & $22.00(18.00-27.50)$ & $22.00(18.75-27.25)$ & 0.696 \\
\hline $\mathrm{PaCO}_{2}(\mathrm{mmHg})$ & $41.75(31.72-60.97)$ & $39.15(32.15-53.55)$ & 0.671 \\
\hline $\mathrm{PaO}_{2} / \mathrm{FiO}_{2}(\mathrm{mmHg})$ & 130.78 (83.76-259.29) & $255.71(200.05-320.44)$ & 0.001 \\
\hline$(A-a) \mathrm{DO}_{2}$ & $183.25(50.71-412.68)$ & $56.12(21.37-166.99)$ & 0.003 \\
\hline \multicolumn{4}{|c|}{ Vital sign and arterial blood gas before extubation } \\
\hline Heart rate on ventilation & $84.50(74.25-101.75)$ & $85.00(68.00-90.25)$ & 0.198 \\
\hline Respiratory rate on ventilation & $18.00(16.00-21.00)$ & $17.00(15.00-20.00)$ & 0.155 \\
\hline $\mathrm{PaCO}_{2}$ on ventilation $(\mathrm{mmHg})$ & $34.75(30.05-40.35)$ & $34.40(28.70-36.15)$ & 0.051 \\
\hline $\mathrm{PaO}_{2} / \mathrm{FiO}_{2}$ on ventilation $(\mathrm{mmHg})$ & $288.00(208.31-363.81)$ & $333.75(279.37-379.37)$ & 0.069 \\
\hline$(\mathrm{A}-\mathrm{a}) \mathrm{DO}_{2}$ at spontaneous breathing trial & 138.71 (95.60-167.74) & $130.20(88.29-130.20)$ & 0.478 \\
\hline
\end{tabular}


Table 1. Continued

\begin{tabular}{|c|c|c|c|}
\hline Characteristics & $\operatorname{HFNC}(n=84)$ & LFOS $(n=34)$ & P-value \\
\hline \multicolumn{4}{|l|}{ High risk patient } \\
\hline Age older than 65 years & $65(77.4)$ & $20(58.8)$ & 0.042 \\
\hline Body mass index higher than $30 \mathrm{~kg} / \mathrm{m}^{2}$ & $7(8.3)$ & $2(5.9)$ & $1.000^{\mathrm{a}}$ \\
\hline Ventilator duration more than 7 days & $30(35.7)$ & $7(20.6)$ & 0.109 \\
\hline Charlson comorbidity index of 2 or more & 33 (39.3) & $7(20.6)$ & 0.052 \\
\hline APACHE II score of more than 12 & 80 (95.2) & $32(94.1)$ & 0.802 \\
\hline Heart failure as a cause of intubation & $3(3.6)$ & 0 & $0.556^{\mathrm{a}}$ \\
\hline Moderate to severe COPD & 16 (19.0) & 0 & $0.005^{\mathrm{a}}$ \\
\hline Failure with first SBT trial & $52(61.9)$ & $17(50.0)$ & 0.235 \\
\hline Duration of mechanical ventilation before extubation (hr) & $120.3(74.9-213.8)$ & $81.93(47.45-139.09)$ & 0.012 \\
\hline Hospital day before extubation trial (day) & $7.5(4.00-10.75)$ & $4.5(3.00-7.25)$ & 0.005 \\
\hline
\end{tabular}

Values are presented as number (\%) or median (interquartile range).

HFNC: high-flow nasal cannula; LFOS: Iow-flow oxygen system; APACHE: Acute Physiologic and Chronic Health Evaluation; ICU: intensive care unit; $\mathrm{PaCO}_{2}$ : arterial partial pressure of carbon dioxide; $\mathrm{PaO}_{2} / \mathrm{FiO}_{2}$ : ratio of arterial oxygen partial pressure to fractional inspired oxygen; $(\mathrm{A}-\mathrm{a}) \mathrm{DO} \mathrm{O}_{2}$ : alveolararterial oxygen difference; COPD: chronic obstructive pulmonary disease; SBT: spontaneous breathing trial.

${ }^{a}$ Fisher exact test; ${ }^{6}$ Type of respiratory failure can be classified according to each group, if it satisfies both criteria; ${ }^{~}$ Respiratory failure that was not satisfy each criterion.

Table 2. Clinical outcome after extubation between two groups

\begin{tabular}{|c|c|c|c|c|}
\hline Variable & $\operatorname{HFNC}(n=84)$ & $\operatorname{LFOS}(n=34)$ & $x^{2}$ & P-value \\
\hline \multicolumn{5}{|l|}{ Reintubation } \\
\hline Early reintubation (in $72 \mathrm{hr}$ ) & $8(9.5)$ & $3(8.8)$ & - & $1.000^{\mathrm{a}}$ \\
\hline Time to reintubation & $10.41(1.51-62.37)$ & $5.00(4.17-43.85)$ & & $0.838^{\mathrm{b}}$ \\
\hline Reintubation in $168 \mathrm{hr}$ & $15(17.9)$ & $3(8.8)$ & 1.528 & 0.216 \\
\hline Time to reintubation & $69.00(2.58-100.82)$ & $5.00(4.17-43.85)$ & & $0.260^{b}$ \\
\hline Delayed reintubation (72-168 hr) & $7 / 76^{c}(9.2)$ & $0 / 31^{c}$ & - & $0.105^{\mathrm{a}}$ \\
\hline \multicolumn{5}{|l|}{ Postextubation respiratory failure } \\
\hline Hypoxia & $7(8.3)$ & $4(11.8)$ & - & $0.727^{a}$ \\
\hline Hypercapnia & $2(2.4)$ & $3(8.8)$ & - & $0.143^{\mathrm{a}}$ \\
\hline Tachypnea & $14(16.7)$ & $6(17.6)$ & 0.017 & 0.898 \\
\hline All types of respiratory failure & $21(25.0)$ & $11(32.4)$ & 0.662 & 0.416 \\
\hline \multicolumn{5}{|l|}{ Clinical outcome } \\
\hline Tracheostomy & $5(6.0)$ & $1(2.9)$ & - & $0.672^{\mathrm{a}}$ \\
\hline In hospital mortality & $12(14.3)$ & $3(8.8)$ & - & $0.549^{a}$ \\
\hline Hospital day & $27.5(16.0-49.7)$ & $14.50(9.0-31.0)$ & - & $0.001^{b}$ \\
\hline
\end{tabular}

Values are presented as number (\%) or median (interquartile range).

HFNC: high-flow nasal cannula; LFOS: low-flow oxygen system.

${ }^{a}$ Fisher exact test; ${ }^{b}$ Mann-Whitney U-test; ${ }^{c}$ Number/total number.

gen difference (183.25 vs. $56.12, \mathrm{P}=0.003$ ). Patients with certain high-risk factors such as age older than 65 years $(77.4 \%$ vs. $58.8 \% ; \mathrm{P}=0.042)$ and moderate to severe COPD (19.0\% vs. $0 \% ; \mathrm{P}=0.005$ ) were more frequently found in the HFNC group.

The baseline laboratory findings in the two groups were also analyzed (Supplementary Table 1). In the baseline labo- ratory findings before intubation, a high neutrophil fraction ( $80.50 \%$ vs. $73.70 \%, P=0.045$ ), high potassium level (4.15 vs. 3.76 $\mathrm{mmol} / \mathrm{L}, \mathrm{P}=0.003)$, and low calcium concentration (8.44 vs. $8.83 \mathrm{mmol} / \mathrm{L}, \mathrm{P}=0.032$ ) were shown in the HFNC group. Low albumin at extubation was also observed in the HFNC group (2.77 vs. $3.00 \mathrm{~g} / \mathrm{dl}, \mathrm{P}=0.010$ ). 


\section{Results of Extubation: PERF and Reintubation}

The occurrences of reintubation and PERF were analyzed (Table 2). The early reintubation rate was eight of $84(9.5 \%)$ and three of $34(8.8 \%)$, respectively $(\mathrm{P}=1.000)$. The occurrences of all types of respiratory failures in both groups were 21 of 84 (25.0\%) and 11 of $34(32.4 \%)$, respectively $(\mathrm{P}=0.416)$. Subanalysis according to subtype of respiratory failure also did not show any statistical difference (Table 2). Hypoxic and hypercapnic respiratory failure occurred in seven of $84(8.3 \%)$ and two of $84(2.4 \%)$ patients in the HFNC group, respectively, and in four of $34(11.8 \%)$ and three of $34(8.8 \%)$ patients in the LFOS group.

In the additional analysis carried out during 168 hours, seven patients in the HFNC group had progressed to reintubation but showed no statistical difference in comparison with the LFOS group. The delayed reintubation rate was seven of 76 (9.2\%) and none of 31 , respectively $(\mathrm{P}=0.105)$. Occurrence of any type of respiratory failure in 48 hours in those who received HFNC was higher in the early reintubation group $(6 / 8,75.0 \%)$ and delayed reintubation group $(4 / 7,57.1 \%)$ versus the nonreintubation group $(11 / 69,15.9 \% ; \mathrm{P}=0.000)$. Time to reintubation, in-hospital mortality rate, and tracheostomy rate did not show a statistical difference between the two groups (Table 2). The hospital stay of the HFNC group was longer than that of the LFOS group (27.5 vs. 14.50 days; $\mathrm{P}=0.001$ ).

\section{Physiologic Effects of HFNC after Extubation}

To elucidate the physiologic effects of HFNC on heart rate, respiratory rate, $\mathrm{PaO}_{2} / \mathrm{FiO}_{2}$, and $\mathrm{PaCO}_{2}$ compared with LFOS, patient vital signs and arterial blood gas after extubation were analyzed according to time. Prior to extubation, baseline heart rate, respiratory rate, $\mathrm{PaCO}_{2}$, and $\mathrm{PaO}_{2} / \mathrm{FiO}_{2}$ were not significantly different between the groups (Figure 2, Supplementary Table 2).

Heart rate during the SBT and at 1 hour after extubation was higher in the HFNC group (Mann-Whitney U-test, $\mathrm{P}=0.014$ in SBT and $\mathrm{P}=0.018$ at 1 hour after extubation extubation). Compared with heart rate in SBT, the heart rate stabilized after 24 hours in the HFNC group (Friedman test, $\chi^{2}=27.033, \mathrm{P}=0.000$; Mann-Whitney $\mathrm{U}$-test, $\mathrm{P}=0.001$ at 24 hours after extubation and $\mathrm{P}=0.001$ at 48 hours after extubation). No statistically significant difference was found in respiratory rate, $\mathrm{PaCO}_{2}$, and $\mathrm{PaO}_{2} / \mathrm{FiO}_{2}$ between each time compared with the parameters during the SPT.

\section{Predictors for Reintubation and Delayed Reintubation in the HFNC Group}

Variables including underlying disease, cause of mechanical ventilation, and high-risk factors were analyzed to determine the risk factors that influence reintubations (Table 3). No risk factors were found except longer hospital stay before extuba-
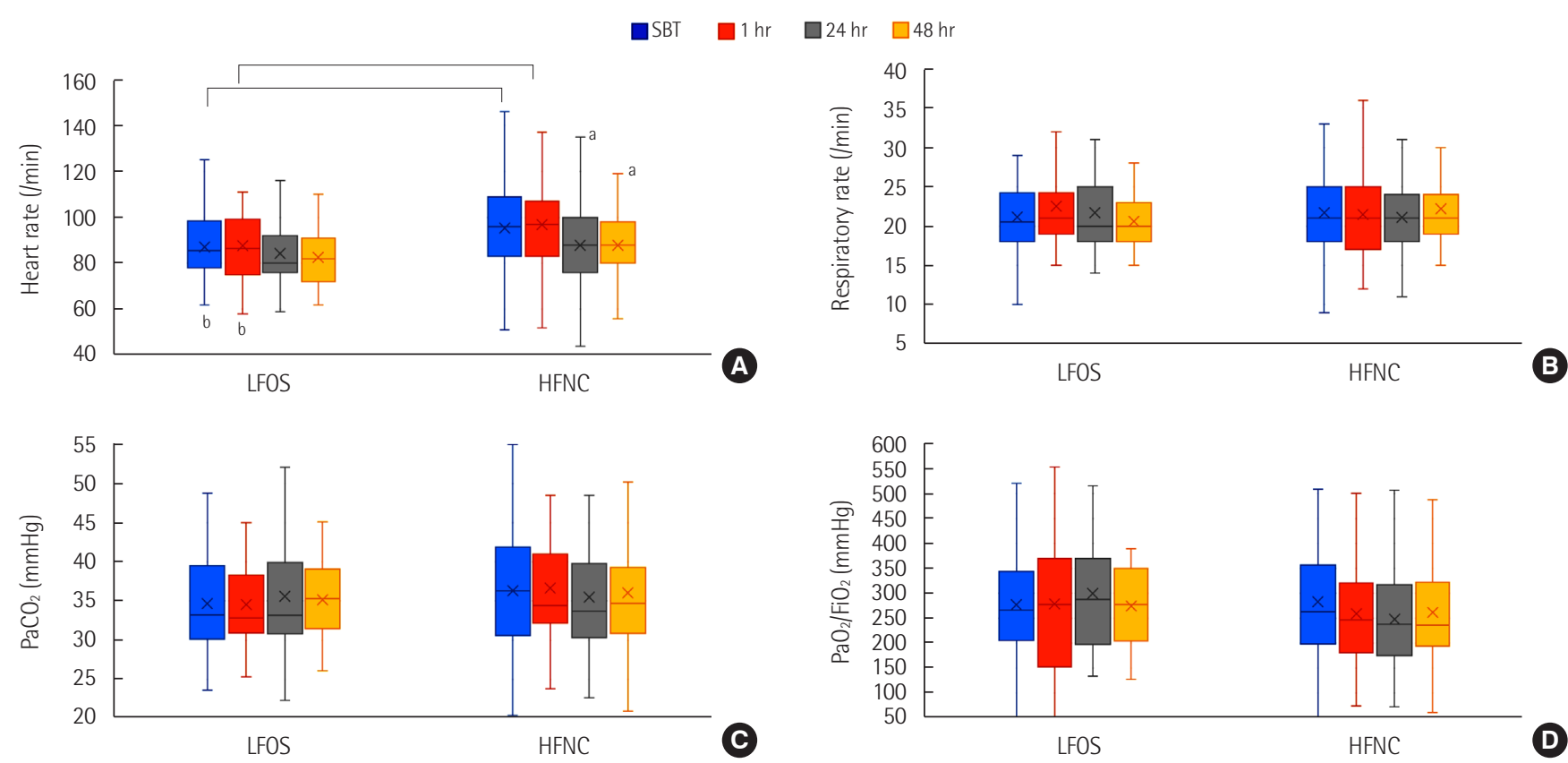

Figure 2. Physiologic parameters after extubation. (A) Heart rate. (B) Respiratory rate. (C) Arterial partial pressure of carbon dioxide $\left(\mathrm{PaCO}_{2}\right)$. (D) The ratio of arterial oxygen partial pressure to fractional inspired oxygen $\left(\mathrm{PaO}_{2} / \mathrm{FiO}_{2}\right)$. LFOS: low-flow oxygen system; HFNC: high-flow nasal cannula; SBT: spontaneous breathing trial. aStatically significant difference between SBTs at each time after extubation; ${ }^{\text {bStatically }}$ significant difference between HFNC and LFOS at the same time. 
Table 3. Predictor for reintubation in HFNC group

\begin{tabular}{|c|c|c|c|}
\hline Characteristics & Non-reintubation $(n=69)$ & Reintubation $(n=15)$ & P-value \\
\hline Male sex & $49(71.0)$ & $11(73.3)$ & $1.000^{\mathrm{a}}$ \\
\hline Age (yr) & $74.0(65.50-80.50)$ & $72.00(67.00-74.00)$ & 0.245 \\
\hline Height (cm) & $162.0(158.0-170.0)$ & $164.50(160.00-165.00)$ & 0.711 \\
\hline Body weight (kg) & $58.0(50.0-70.0)$ & $55.30(50.00-60.00)$ & 0.656 \\
\hline Body mass index $\left(\mathrm{kg} / \mathrm{m}^{2}\right)$ & $22.7(18.7-24.9)$ & $22.03(19.59-23.44)$ & 0.717 \\
\hline \multicolumn{4}{|l|}{ Underlying disease } \\
\hline Diabetes mellitus & $15(21.7)$ & $4(26.7)$ & $0.736^{\mathrm{a}}$ \\
\hline Hypertension & $25(36.2)$ & $6(40.0)$ & 0.784 \\
\hline Malignant disease & $6(8.7)$ & $4(26.7)$ & $0.073^{\mathrm{a}}$ \\
\hline Chronic respiratory disease & $40(58.0)$ & $7(46.7)$ & 0.424 \\
\hline Chronic heart disease & $18(26.1)$ & $4(26.7)$ & $1.000^{\mathrm{a}}$ \\
\hline Chronic liver disease & $1(1.4)$ & 0 & $1.000^{\mathrm{a}}$ \\
\hline Chronic renal disease & $7(10.1)$ & $4(26.7)$ & $0.102^{\mathrm{a}}$ \\
\hline Neurologic disease & $20(29.0)$ & $7(46.7)$ & $0.226^{a}$ \\
\hline \multicolumn{4}{|l|}{ Cause of mechanical ventilation } \\
\hline Pneumonia & $36(52.2)$ & $9(60.0)$ & 0.776 \\
\hline Airway disease & $9(13.0)$ & $4(26.7)$ & $0.235^{\mathrm{a}}$ \\
\hline Hemoptysis & $3(4.3)$ & 0 & $1.000^{\mathrm{a}}$ \\
\hline Drug intoxication & $13(18.8)$ & $1(6.7)$ & $0.447^{\mathrm{a}}$ \\
\hline Post operation & $2(2.9)$ & 0 & $1.000^{\mathrm{a}}$ \\
\hline Heat failure & $3(4.3)$ & 0 & $1.000^{\mathrm{a}}$ \\
\hline Others & $3(4.3)$ & $1(6.7)$ & $0.552^{\mathrm{a}}$ \\
\hline \multicolumn{4}{|l|}{ Type of respiratory failure at intubation ${ }^{b}$} \\
\hline Tachypneic respiratory failure & $5(7.2)$ & $1(6.7)$ & $1.000^{\mathrm{a}}$ \\
\hline Hypercapnic respiratory failure & $31(44.9)$ & $7(46.7)$ & 0.902 \\
\hline Hypoxic respiratory failure & $22(31.9)$ & $1(6.7)$ & $0.058^{\mathrm{a}}$ \\
\hline Others ${ }^{c}$ & $15(21.7)$ & $7(46.7)$ & $0.058^{\mathrm{a}}$ \\
\hline \multicolumn{4}{|l|}{ Severity index } \\
\hline APACHE II score at ICU admission & $22.0(17.50-25.00)$ & $22.00(19.00-25.00)$ & 0.516 \\
\hline APACHE II score at extubation & $17.0(15.0-19.0)$ & $16.00(13.00-22.00)$ & 0.541 \\
\hline \multicolumn{4}{|c|}{ Vital sign and arterial blood gas before intubation } \\
\hline Heart rate & $100.00(84.00-124.50)$ & $101.00(88.00-118.00)$ & 0.820 \\
\hline Respiratory rate & $22.00(18.00-26.00)$ & $22.00(18.00-28.00)$ & 0.977 \\
\hline $\mathrm{PaCO}_{2}(\mathrm{mmHg})$ & $44.90(30.50-60.95)$ & $38.60(32.00-86.00)$ & 0.356 \\
\hline $\mathrm{PaO}_{2} / \mathrm{FiO}_{2}(\mathrm{mmHg})$ & $131.97(86.90-256.19)$ & 120.86 (80.12-291.90) & 0.907 \\
\hline$(A-a) \mathrm{DO}_{2}$ & $186.97(48.71-411.96)$ & $179.53(50.43-465.58)$ & 0.532 \\
\hline \multicolumn{4}{|c|}{ Vital sign and arterial blood gas before extubation } \\
\hline Heart rate on ventilation & $82.00(73.50-101.00)$ & 87.00 (76.00-109.00) & 0.272 \\
\hline Respiratory rate on ventilation & $18.00(16.00-21.00)$ & $18.00(15.00-20.00)$ & 0.366 \\
\hline $\mathrm{PaCO}_{2}$ on ventilation $(\mathrm{mmHg})$ & $34.60(30.50-40.30)$ & $35.40(27.70-46.80)$ & 0.717 \\
\hline $\mathrm{PaO}_{2} / \mathrm{FiO}_{2}$ on ventilation $(\mathrm{mmHg})$ & $286.75(215.62-361.00)$ & $321.00(165.75-400.00)$ & 0.939 \\
\hline$(\mathrm{A}-\mathrm{a}) \mathrm{DO}_{2}$ at spontaneous breathing trial & $143.62(110.02-166.10)$ & 123.42 (92.25-178.92) & 0.640 \\
\hline
\end{tabular}


Table 3. Continued

\begin{tabular}{|c|c|c|c|}
\hline Characteristics & Non-reintubation $(n=69)$ & Reintubation $(n=15)$ & P-value \\
\hline \multicolumn{4}{|l|}{ High risk patient } \\
\hline Age older than 65 years & $53(76.8)$ & $12(80.0)$ & $1.000^{\mathrm{a}}$ \\
\hline Body mass index higher than $30 \mathrm{~kg} / \mathrm{m}^{2}$ & $6(8.7)$ & $1(6.7)$ & $1.000^{\mathrm{a}}$ \\
\hline Ventilator duration more than 7 days & $22(31.9)$ & $8(53.3)$ & 0.116 \\
\hline Charlson comorbidity index of 2 or more & $26(37.7)$ & $7(46.7)$ & $0.518^{\mathrm{a}}$ \\
\hline APACHE II score of more than 12 & $66(95.7)$ & 14 (93.3) & $0.552^{\mathrm{a}}$ \\
\hline Heart failure as a cause of intubation & $3(4.3)$ & 0 & $1.000^{\mathrm{a}}$ \\
\hline Moderate to severe COPD & $15(21.7)$ & $1(6.7)$ & $0.282^{\mathrm{a}}$ \\
\hline Failure with first SBT trial & $40(58.0)$ & $12(80.0)$ & 0.111 \\
\hline Duration of mechanical ventilation before extubation (hr) & 117.15 (70.71-210.29) & $181.46(82.83-273.66)$ & 0.197 \\
\hline Hospital day before extubation trial (day) & $6.00(4.00-10.00)$ & $9.00(8.00-14.00)$ & 0.036 \\
\hline
\end{tabular}

Values are presented as number (\%) or median (interquartile range).

HFNC: high-flow nasal cannula; APACHE: Acute Physiologic and Chronic Health Evaluation; ICU: intensive care unit; PaCO ${ }_{2}$ : arterial partial pressure of carbon dioxide; $\mathrm{PaO}_{2} / \mathrm{FiO}_{2}$ : ratio of arterial oxygen partial pressure to fractional inspired oxygen; $(\mathrm{A}-\mathrm{a}) \mathrm{DO}_{2}$ : alveolar-arterial oxygen difference; COPD: chronic obstructive pulmonary disease; SBT: spontaneous breathing trial.

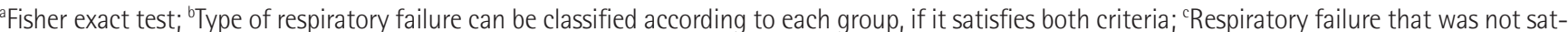
isfy each criterion.

tion (9.00 [8.00-14.00] vs. 6.00 [4.00-10.00], $\mathrm{P}=0.036)$. There was no difference in the type of respiratory failure at intubation in the HFNC group. Although there was no significant difference, hypoxemic respiratory failure was more frequently found in the nonreintubation group versus the reintubation group (22/69 [31.9\%] vs. 1/15 [6.7\%], $\mathrm{P}=0.058)$.

To find the cause of delayed reintubation in the HFNC group, multiple variables were analyzed between the delayed reintubation group and nonreintubation group (Supplementary Table 3). There was no difference among these groups except more frequent basement renal disease (3/7 [42.9\%] vs. 7/69 $[10.1 \%], \mathrm{P}=0.044)$ in the delayed-reintubation group.

\section{DISCUSSION}

An obvious benefit of HFNC in the context of the prevention of PERF and reintubation versus in the LFOS group at 72 hours after extubation was not observed in high-risk patients. Regarding physiologic aspects, HFNC might have helped to stabilize the heart rate, but no effect on stabilization of the respiratory rate, $\mathrm{PaCO}_{2}$, and $\mathrm{PaO}_{2} / \mathrm{FiO}_{2}$ was noted.

Contrary to the recent meta-analysis and several other articles that reported the superiority of HFNC over LFOS after extubation, in this study, no significant benefits were observed in preventing PERF and reintubation $[4,17,18]$. However, the results of previous studies cannot be generalized due to the limited constitution of study populations (Table 4) $[4,17,18]$.
In postsurgical patients, HFNC has continued to show a benefit over LFOS after extubation $[13,14,16]$. However, it is not generalized to nonsurgical patients. Only three previous studies directly compared HFNC and LFOS in medical patients and presented confusing results (Table 4) [4,12,15]. Hernández et al. [4] showed a low PERF ratio and low reintubation rate in HFNC versus conventional LFOS in low-risk patients after extubation. However, this group did not compare the HFNC to LFOS in high-risk patients directly. Fernandez et al. [12] studied the efficacy of HFNC in high-risk patients who suffered from nonhypercapnic respiratory failure versus conventional LFOS but reported inconclusive results due to low recruitment. The other study conducted by Song et al. [15] in acute respiratory failure patients with mixed risk also failed to prove the protection of reintubation. In conclusion, according to the literature review, HFNC after extubation as adjunctive oxygen therapy in low-risk or postsurgical patients might be effective, but there is no conclusion regarding high-risk patients.

In our study, physicians preferred HFNC over LFOS in highrisk patients who were older than 65 years and had moderate to severe COPD and/or neurologic disease, which are wellknown risk factors for reintubation [19]. HFNC is also more likely to be applied in patients with a high baseline alveolararterial oxygen difference that implies impaired gas exchange and in those with longer ventilator duration before extubation, which is a risk factor for reintubation $[1,20]$. For these reasons, it is worth noting that similar PERF and reintubation ratios were 
Table 4. Literature review for previous studies comparing HFNC to other oxygen delivery devices after extubation

\begin{tabular}{|c|c|c|c|c|c|c|}
\hline Study & $\begin{array}{l}\text { Study's charac- } \\
\text { teristics }\end{array}$ & Patient's characteristics & Control & Reintubation & PERF & Physiologic aspect \\
\hline Futier et al. [13] & Prospective RCT & $\begin{array}{l}\text { Surgical patient after major } \\
\text { abdominal surgery }\end{array}$ & LFOS & No difference & No difference & - \\
\hline Dhillon et al. [16] & Retrospective & Critically ill surgical patient & LFOS & No difference ${ }^{\mathrm{a}}$ & - & - \\
\hline Yu et al. [14] & Prospective RCT & $\begin{array}{l}\text { Surgical patient after thoraco- } \\
\text { scopic lobectomy }\end{array}$ & LFOS & $\begin{array}{l}\text { Less reintubation in } \\
\text { HFNC }\end{array}$ & $\begin{array}{l}\text { Less hypoxemic } \\
\text { respiratory failure } \\
\text { in HFNC }\end{array}$ & $\begin{array}{l}\text { Better oxygenation, re- } \\
\text { duction of respiratory } \\
\text { rate in HFNC }\end{array}$ \\
\hline Hernández et al. [6] & Prospective RCT & High risk & NIV & Not inferior in HFNC & Not inferior in HFNC & No difference \\
\hline Yoo et al. [5] & Retrospective & Mixed risk & NIV & No difference & - & - \\
\hline Maggiore et al. [3] & Prospective RCT & Mixed risk & LFOS $^{b}$ & $\begin{array}{l}\text { Less reintubation in } \\
\text { HFNC }\end{array}$ & Less PERF in HFNC & $\begin{array}{l}\text { Better oxygenation, re- } \\
\text { duction of respiratory } \\
\text { rate in HFNC }\end{array}$ \\
\hline Hernández et al. [4] & Prospective RCT & Low risk & LFOS & $\begin{array}{l}\text { Less reintubation in } \\
\text { HFNC }\end{array}$ & Less PERF in HFNC & No difference \\
\hline Fernandez et al. [12] & Prospective RCT & $\begin{array}{l}\text { Mixed risk, but include only } \\
\text { hypercapnic patient }\end{array}$ & LFOS & No difference & No difference & - \\
\hline Song et al. [15] & Prospective RCT & Mixed risk & LFOS & No difference & - & $\begin{array}{l}\text { Better oxygenation, re- } \\
\text { duction of respiratory } \\
\text { rate in HFNC }\end{array}$ \\
\hline This study & Retrospective & High risk & LFOS & No difference & No difference & No difference $e^{c}$ \\
\hline
\end{tabular}

HFNC: high-flow nasal cannula; PERF: postextubation respiratory failure; RCT: randomized controlled trial; LFOS: low-flow oxygen system; NIV: noninvasive ventilation.

an multivariable analysis, HFNC is associated with a lower risk of reintubation; ${ }^{b}$ This study only used the venturi mask as LFOS; ' In this study, HFNC shows stabilization of the heart rate after extubation.

shown in the HFNC patients who had more risk factors.

In the previous two studies, HFNC stabilized the respiratory rate and improved the oxygenation $[15,21,22]$. In the previous study by Frat et al. [22], in acute respiratory failure, HFNC is related to reduced mortality and low reintubation in severe hypoxemia patients $\left(\mathrm{PaO}_{2} / \mathrm{FiO}_{2}<200 \mathrm{mmHg}\right)$ compared with standard oxygen and NIV. The authors [22] insisted that this effect originates from a reduction in work of breathing and improvement of gas exchange. However, these effects were not found in this study. The initial lower $\mathrm{PaO}_{2} / \mathrm{FiO}_{2}$ and high alveolar-arterial oxygen gradient in the HFNC group could explain these unfavorable results. Similar to previous studies, no reduction of $\mathrm{PaCO}_{2}$ was observed here $[4,12,15]$. This result differs from that in some other reports, which showed reduction in vitro and in other clinical situations, except for extubation. Therefore, $\mathrm{PaCO}_{2}$ reduction may not be expected generally in the use of HFNC after extubation.

In this study, patients who received HFNC had lower $\mathrm{PaO}_{2} /$ $\mathrm{FiO}_{2}$ versus those who received LFOS. Although not statistically significant, considering the more frequent preintubation hypoxemic respiratory failure in the nonreintubation group, which was expected to be improved by HFNC and have no ef- fect on respiratory rate and $\mathrm{PaCO}_{2}, \mathrm{HFNC}$ may play a role more in in nonhypercapnic respiratory failure than ventilatory failure after extubation.

To determine who will obtain a benefit from HFNC after extubation in high-risk patients, a subanalysis was performed. Longer hospital stay before extubation, which reflects the possibility of poor patient condition, might be linked with a higher risk for reintubation.

Although no statistical difference was shown in time to reintubation and time to respiratory failure, it is worth noting that a tendency of delayed reintubation was shown in the HFNC group like in previous research $[5,12]$. The reason for the tendency of delayed reintubation in our study is not clear. In subanalysis, when considering the risk factors for delayed reintubation, there was no significant difference except in basement renal disease between the delayed-reintubation group and non-reintubation group. Considering that more than $50 \%$ of patients in the delayed-reintubation group already suffered respiratory failure within 48 hours, there is a possibility of a physician's hesitancy to complete early reintubation due to an expectation about HFNC's stabilizing effect. Also, there is the possibility of HFNC hiding the aggravation of PERF, resulting 
in erroneous determination of extubation success. Further evaluation is needed to clarify this undesirable complication.

Our study has several strengths. First, compared with the previous studies that only included limited characteristics [4, 12], the patients in this study had more diverse characteristics including hypercapnic respiratory failure. Second, in this study, we provided information about the physiologic changes and serial arterial blood gas analysis findings after extubation with a longer duration than in the previous studies. Therefore, we can better comment on the long-term effects of HFNC after extubation. Third, due to the nature of retrospective studies, this study reflects a real-world situation without artificial interventions.

This study also has some limitations. First, due to the study design (single-center, retrospective investigation), confounding factors and bias may be present. Furthermore, important information including parameters of the mechanical ventilator that were unrecorded in the medical record could not be analyzed. For this reason, the well-known predictors for PERF and reintubation including rapid shallow breathing index, maximal inspiratory pressure, and modified burns wean assessment program outcomes could not be analyzed [23]. Second, we only compared HFNC to LFOS and did not compare it to NIV. To clarify the benefit of HFNC on postextubation, especially in high-risk patients, additional study including NIV is necessary. Third, the number of study participants and reintubation rates are too small to show statistical significance. The findings on who receives benefit from HFNC and who will progress to delayed reintubation cannot be deemed statistically significant due to the small number of study participants.

In conclusion, no difference was observed in the PERF and reintubation ratios between the HFNC and LFOS groups at 72 hours after extubation. It is better to understand HFNC after extubation does not work than to do further prospective randomized controlled studies to clarify this efficacy and concern in high-risk patients. Caution is needed due to the tendency of delayed reintubation of the HFNC group. In terms of physiologic aspects, HFNC after extubation might be linked to stabilization of the heart rate after extubation.

\section{CONFLICT OF INTEREST}

No potential conflict of interest relevant to this article was reported.

\section{ORCID}

Minhyeok Lee ～https://orcid.org/0000-0002-0098-8106
Ji Hye Kim

https://orcid.org/0000-0003-4677-0513

In Beom Jeong

Ji Woong Son

https://orcid.org/0000-0001-9587-5122

Moon Jun Na

https://orcid.org/0000-0001-5951-5058

Sun Jung Kwon

https://orcid.org/0000-0002-0941-5806

https://orcid.org/0000-0002-0361-8629

\section{AUTHOR CONTRIBUTIONS}

Conceptualization: SJK. Data curation: ML. Formal analysis: ML. Methodology: SJK. Visualization: ML. Writing - original draft: ML. Writing - review \& editing: JHK, IBJ, JWS, MJN, SJK.

\section{SUPPLEMENTARY MATERIALS}

The online-only supplement data are available with this article online: https://doi.org/10.4266/acc.2018.00311.

\section{REFERENCES}

1. Epstein SK. Decision to extubate. Intensive Care Med 2002; 28:535-46

2. Nava S, Gregoretti C, Fanfulla F, Squadrone E, Grassi M, Carlucci A, et al. Noninvasive ventilation to prevent respiratory failure after extubation in high-risk patients. Crit Care Med 2005;33:2465-70.

3. Maggiore SM, Idone FA, Vaschetto R, Festa R, Cataldo A, Antonicelli $\mathrm{F}$, et al. Nasal high-flow versus venturi mask oxygen therapy after extubation: effects on oxygenation, comfort, and clinical outcome. Am J Respir Crit Care Med 2014;190:282-8.

4. Hernández G, Vaquero C, González P, Subira C, Frutos-Vivar F, Rialp G, et al. Effect of postextubation high-flow nasal cannula vs conventional oxygen therapy on reintubation in lowrisk patients: a randomized clinical trial. JAMA 2016;315:135461.

5. Yoo JW, Synn A, Huh JW, Hong SB, Koh Y, Lim CM. Clinical efficacy of high-flow nasal cannula compared to noninvasive ventilation in patients with post-extubation respiratory failure. Korean J Intern Med 2016;31:82-8.

6. Hernández G, Vaquero C, Colinas L, Cuena R, González P, Canabal A, et al. Effect of postextubation high-flow nasal cannula vs noninvasive ventilation on reintubation and postextubation respiratory failure in high-risk patients: a randomized clinical trial. JAMA 2016;316:1565-74.

7. Ornico SR, Lobo SM, Sanches HS, Deberaldini M, Tófoli LT, Vidal AM, et al. Noninvasive ventilation immediately after extubation improves weaning outcome after acute respiratory failure: a randomized controlled trial. Crit Care 2013;17:R39. 
8. Carron M, Freo U, BaHammam AS, Dellweg D, Guarracino F, Cosentini R, et al. Complications of non-invasive ventilation techniques: a comprehensive qualitative review of randomized trials. Br J Anaesth 2013;110:896-914.

9. Nishimura M. High-flow nasal cannula oxygen therapy in adults. J Intensive Care 2015;3:15.

10. Fricke K, Tatkov S, Domanski U, Franke KJ, Nilius G, Schneider H. Nasal high flow reduces hypercapnia by clearance of anatomical dead space in a COPD patient. Respir Med Case Rep 2016;19:115-7.

11. Frizzola M, Miller TL, Rodriguez ME, Zhu Y, Rojas J, Hesek A, et al. High-flow nasal cannula: impact on oxygenation and ventilation in an acute lung injury model. Pediatr Pulmonol 2011;46:67-74.

12. Fernandez R, Subira C, Frutos-Vivar F, Rialp G, Laborda C, Masclans JR, et al. High-flow nasal cannula to prevent postextubation respiratory failure in high-risk non-hypercapnic patients: a randomized multicenter trial. Ann Intensive Care 2017;7:47.

13. Futier E, Paugam-Burtz C, Godet T, Khoy-Ear L, Rozencwajg S, Delay JM, et al. Effect of early postextubation high-flow nasal cannula vs conventional oxygen therapy on hypoxaemia in patients after major abdominal surgery: a French multicentre randomised controlled trial (OPERA). Intensive Care Med 2016;42:1888-98.

14. Yu Y, Qian X, Liu C, Zhu C. Effect of high-flow nasal cannula versus conventional oxygen therapy for patients with thoracoscopic lobectomy after extubation. Can Respir J 2017;2017: 7894631

15. Song HZ, Gu JX, Xiu HQ, Cui W, Zhang GS. The value of highflow nasal cannula oxygen therapy after extubation in patients with acute respiratory failure. Clinics 2017;72:562-7.
16. Dhillon NK, Smith EJT, Ko A, Harada MY, Polevoi D, Liang R, et al. Extubation to high-flow nasal cannula in critically ill surgical patients. J Surg Res 2017;217:258-64.

17. Huang HW, Sun XM, Shi ZH, Chen GQ, Chen L, Friedrich JO, et al. Effect of high-flow nasal cannula oxygen therapy versus conventional oxygen therapy and noninvasive ventilation on reintubation rate in adult patients after extubation: a systematic review and meta-analysis of randomized controlled trials. J Intensive Care Med 2018;33:609-23.

18. Ni YN, Luo J, Yu H, Liu D, Liang BM, Yao R, et al. Can high-flow nasal cannula reduce the rate of reintubation in adult patients after extubation? A meta-analysis. BMC Pulm Med 2017;17:142.

19. Vallverdú I, Calaf N, Subirana M, Net A, Benito S, Mancebo J. Clinical characteristics, respiratory functional parameters, and outcome of a two-hour T-piece trial in patients weaning from mechanical ventilation. Am J Respir Crit Care Med 1998;158: 1855-62.

20. Lee KH, Hui KP, Chan TB, Tan WC, Lim TK. Rapid shallow breathing (frequency-tidal volume ratio) did not predict extubation outcome. Chest 1994;105:540-3.

21. Rittayamai N, Tscheikuna J, Rujiwit P. High-flow nasal cannula versus conventional oxygen therapy after endotracheal extubation: a randomized crossover physiologic study. Respir Care 2014;59:485-90.

22. Frat JP, Thille AW, Mercat A, Girault C, Ragot S, Perbet S, et al. High-flow oxygen through nasal cannula in acute hypoxemic respiratory failure. N Engl J Med 2015;372:2185-96.

23. Jeong ES, Lee K. Clinical application of modified burns wean assessment program scores at first spontaneous breathing trial in weaning patients from mechanical ventilation. Acute Crit Care 2018;33:260-8. 
Supplementary Table 1. Initial laboratory findings in both groups

\begin{tabular}{|c|c|c|c|}
\hline Variable & HFNC & LFOS & P-value \\
\hline \multicolumn{4}{|c|}{ Laboratory findings at intubation } \\
\hline $\operatorname{WBC}\left(10^{3} / \mu l\right)$ & 12.95 (9.40-18.90) & $12.70(7.80-15.35)$ & 0.191 \\
\hline Hemoglobin (g/dl) & $11.95(10.83-13.60)$ & $12.80(10.32-14.37)$ & 0.349 \\
\hline Platelet $\left(10^{3} / \mu l\right)$ & 228.00 (179.00-291.75) & $233.00(201.25-289.25)$ & 0.059 \\
\hline Segment neutrophil (\%) & 80.50 (67.55-88.48) & $73.70(59.15-85.55)$ & 0.045 \\
\hline Serum sodium (mmol/L) & $139.00(134.00-141.75)$ & $138.00(134.75-141.25)$ & 0.884 \\
\hline Serum potassium (mmol/L) & $4.15(3.81-4.68)$ & 3.76 (3.39-4.18) & 0.003 \\
\hline Serum calcium (mmol/L) & $8.44(7.75-8.83)$ & $8.83(8.32-9.37)$ & 0.032 \\
\hline Creatinine (mg/dl) & $0.97(0.73-1.41)$ & $1.05(0.83-1.55)$ & 0.255 \\
\hline Pro-BNP (pg/ml) & $1377.00(364.65-3523.5)$ & 281.20 (139.90-911.70) & 0.081 \\
\hline Albumin (g/dl) & $3.37(2.93-3.90)$ & $3.76(2.80-4.22)$ & 0.160 \\
\hline Bilirubin (mg/dl) & $0.69(0.47-0.92)$ & $0.59(0.47-0.96)$ & 0.591 \\
\hline GCS score & $10.00(7.00-13.00)$ & $9.00(6.00-12.25)$ & 0.190 \\
\hline \multicolumn{4}{|c|}{ Laboratory findings at extubation } \\
\hline $\operatorname{WBC}\left(10^{3} / \mu \mathrm{l}\right)$ & $10.75(8.10-13.75)$ & $10.30(7.67-13.95)$ & 0.845 \\
\hline Hemoglobin (g/dl) & $10.60(9.83-11.88)$ & $10.95(9.30-12.07)$ & 0.993 \\
\hline Platelet $\left(10^{3} / \mu \mathrm{l}\right)$ & $183.00(140.25-247.75)$ & $181.50(135.25-215.25)$ & 0.558 \\
\hline Segment neutrophil (\%) & $79.8(74.10-85.80)$ & $81.80(77.40-86.80)$ & 0.308 \\
\hline Serum sodium (mmol/L) & $138.00(135.00-141.00)$ & $138.00(136.00-142.00)$ & 0.865 \\
\hline Serum potassium (mmol/L) & $3.76(3.36-4.23)$ & $3.78(3.49-4.07)$ & 0.934 \\
\hline Creatinine (mg/dl) & $0.67(0.49-0.98)$ & $0.81(0.56-0.96)$ & 0.261 \\
\hline Albumin (g/dl) & $2.77(2.47-3.03)$ & $3.00(2.73-3.34)$ & 0.010 \\
\hline Bilirubin (mg/dl) & $0.65(0.52-1.00)$ & $0.70(0.45-0.92)$ & 0.592 \\
\hline GCS score & $14.00(12.00-15.00)$ & $14.50(11.75-15.00)$ & 0.341 \\
\hline
\end{tabular}

Values are presented as median (interquartile range).

HFNC: high-flow nasal cannula; LFOS: low-flow oxygen system; WBC: white blood cell; BNP: brain natriuretic peptide; GCS: Glasgow coma scale. aMann-Whitney U-test. 
Supplementary Table 2. Physiologic change of vital signs and arterial blood gas after extubation

\begin{tabular}{|c|c|c|c|c|c|}
\hline Variable & HFNC & LFOS & P-value ${ }^{a}$ & P-value ${ }^{b}$ & P-value \\
\hline \multicolumn{6}{|l|}{ Heart rate (/min) } \\
\hline On mechanical ventilator & $84.50(74.25-101.75)$ & $85.00(68.00-90.25)$ & 0.198 & - & - \\
\hline At spontaneous breathing trial & $96.00(83.00-109.00)$ & $85.50(78.00-98.50)$ & 0.014 & - & - \\
\hline Within 1 hour after extubation & $97.00(83.00-107.00)$ & $86.50(76.00-99.25)$ & 0.018 & 0.185 & 0.911 \\
\hline Within 24 hours after extubation & $88.00(76.00-100.00)$ & $80.00(76.00-92.00)$ & 0.182 & 0.001 & 0.119 \\
\hline Within 48 hours after extubation & $88.00(80.00-98.00)$ & $82.00(72.00-91.00)$ & 0.067 & 0.001 & 0.064 \\
\hline Friedman test & $\chi^{2}=27.033, P=0.000$ & $\chi^{2}=8.144, P=0.043$ & & & \\
\hline \multicolumn{6}{|l|}{ Respiratory rate (/min) } \\
\hline On mechanical ventilator & $18.00(16.00-21.00)$ & $17.00(15.00-20.00)$ & 0.155 & - & - \\
\hline At spontaneous breathing trial & $21.00(18.00-25.00)$ & $20.50(18.00-24.25)$ & 0.598 & - & - \\
\hline Within 1 hour after extubation & $21.00(17.00-25.00)$ & $21.00(19.00-24.25)$ & 0.661 & - & - \\
\hline Within 24 hours after extubation & $21.00(19.00-24.00)$ & $20.00(18.00-25.00)$ & 0.667 & - & - \\
\hline Within 48 hours after extubation & $21.00(19.00-24.00)$ & $20.00(18.00-23.00)$ & 0.175 & - & - \\
\hline Friedman test & $\chi^{2}=3.079, P=0.380$ & $\chi^{2}=3.103, P=0.376$ & & & \\
\hline \multicolumn{6}{|l|}{$\mathrm{PaCO}_{2}(\mathrm{mmHg})$} \\
\hline On mechanical ventilator & $34.75(30.05-40.35)$ & $34.40(28.70-36.15)$ & 0.051 & - & - \\
\hline At spontaneous breathing trial & $36.30(30.58-41.90)$ & $33.20(30.13-39.50)$ & 0.278 & - & - \\
\hline Within 1 hour after extubation & $34.40(32.00-41.00)$ & $32.80(30.90-38.30)$ & 0.231 & 0.654 & - \\
\hline Within 24 hours after extubation & $34.00(30.00-40.00)$ & $33.68(33.15-39.75)$ & 0.873 & 0.088 & - \\
\hline Within 48 hours after extubation & $34.70(31.00-39.00)$ & $31.45(35.30-39.20)$ & 0.989 & 0.286 & - \\
\hline Friedman test & $\chi^{2}=10.408, P=0.015$ & $\chi^{2}=4.303, P=0.231$ & & & \\
\hline \multicolumn{6}{|l|}{$\mathrm{PaO}_{2} / \mathrm{FiO}_{2}(\mathrm{mmHg})$} \\
\hline On mechanical ventilator & 288.00 (208.31-363.81) & 333.75 (279.37-379.37) & 0.069 & - & - \\
\hline At spontaneous breathing trial & 261.88 (206.00-339.44) & 297.75 (184.98-384.88) & 0.465 & - & - \\
\hline Within 1 hour after extubation & $246.67(180.77-320.05)$ & $277.25(152.75-370.00)$ & 0.651 & - & - \\
\hline Within 24 hours after extubation & $237.75(175.00-316.75)$ & 287.90 (197.20-369.60) & 0.053 & - & - \\
\hline Within 48 hours after extubation & $236.50(193.00-322.75)$ & $277.00(204.50-350.00)$ & 0.394 & - & - \\
\hline Friedman test & $\chi^{2}=6.768, P=0.080$ & $\chi^{2}=1.711, P=0.634$ & & & \\
\hline
\end{tabular}

Values are presented as median (interquartile range).

HFNC: high-flow nasal cannula; LFOS: low-flow oxygen system; $\mathrm{PaCO}_{2}$ : arterial partial pressure of carbon dioxide; $\mathrm{PaO}_{2} / \mathrm{FiO}_{2}$ : ratio of arterial oxygen partial pressure to fractional inspired oxygen.

aMann-Whitney U-test between HFNC and LFOS; 'Wilcoxon rank sum test between parameters at spontaneous breathing trial and at each time in HFNC group; 'Wilcoxon rank sum test between parameters at spontaneous breathing trial and at each time in LFOS group. 
Supplementary Table 3. Predictor for delayed reintubation compared to non-reintubation in HFNC group

\begin{tabular}{|c|c|c|c|}
\hline Characteristics & Non-reintubation $(n=69)$ & Delayed reintubation $(n=7)$ & P-value \\
\hline Male sex & $49(71.0)$ & $5(71.4)$ & $1.000^{\mathrm{a}}$ \\
\hline Age (yr) & $74.0(65.50-80.50)$ & $74.00(69.00-76.00)$ & 0.893 \\
\hline Height (cm) & $162.0(158.0-170.0)$ & $161.50(160.00-165.00)$ & 0.738 \\
\hline Body weight (kg) & $58.0(50.0-70.0)$ & $55.00(50.00-60.00)$ & 0.843 \\
\hline Body mass index $\left(\mathrm{kg} / \mathrm{m}^{2}\right)$ & $22.7(18.7-24.9)$ & $22.03(19.59-23.44)$ & 0.774 \\
\hline \multicolumn{4}{|l|}{ Underlying disease } \\
\hline Diabetes mellitus & $15(21.7)$ & $2(28.6)$ & $0.650^{\mathrm{a}}$ \\
\hline Hypertension & $25(36.2)$ & $3(42.9)$ & $0.704^{\mathrm{a}}$ \\
\hline Malignant disease & $6(8.7)$ & $1(14.3)$ & $0.506^{a}$ \\
\hline Chronic respiratory disease & $40(58.0)$ & $2(28.6)$ & $0.232^{\mathrm{a}}$ \\
\hline Chronic heart disease & $18(26.1)$ & $3(42.9)$ & $0.387^{\mathrm{a}}$ \\
\hline Chronic liver disease & $1(1.4)$ & 0 & $1.000^{\mathrm{a}}$ \\
\hline Chronic renal disease & $7(10.1)$ & $3(42.9)$ & $0.044^{\mathrm{a}}$ \\
\hline Neurologic disease & $20(29.0)$ & $3(42.9)$ & $0.426^{\mathrm{a}}$ \\
\hline \multicolumn{4}{|l|}{ Cause of mechanical ventilation } \\
\hline Pneumonia & $36(52.2)$ & $4(57.1)$ & $1.000^{\mathrm{a}}$ \\
\hline Airway disease & $9(13.0)$ & $2(28.6)$ & $0.266^{a}$ \\
\hline Hemoptysis & $3(4.3)$ & 0 & $1.000^{\mathrm{a}}$ \\
\hline Drug intoxication & $13(18.8)$ & 0 & $0.596^{\mathrm{a}}$ \\
\hline Post operation & $2(2.9)$ & 0 & $1.000^{\mathrm{a}}$ \\
\hline Heat failure & $3(4.3)$ & 0 & $1.000^{\mathrm{a}}$ \\
\hline Others & $3(4.3)$ & $1(14.3)$ & $0.326^{\mathrm{a}}$ \\
\hline \multicolumn{4}{|l|}{ Type of respiratory failure at intubation ${ }^{b}$} \\
\hline Tachypneic respiratory failure & $5(7.2)$ & 0 & $1.000^{\mathrm{a}}$ \\
\hline Hypercapnic respiratory failure & $31(44.9)$ & $3(42.9)$ & $1.000^{\mathrm{a}}$ \\
\hline Hypoxic respiratory failure & $22(31.9)$ & 0 & $0.100^{\mathrm{a}}$ \\
\hline Others ${ }^{c}$ & $15(21.7)$ & $4(57.1)$ & $0.061^{\mathrm{a}}$ \\
\hline \multicolumn{4}{|l|}{ Severity index } \\
\hline APACHE II score at ICU admission & $22.0(17.50-25.00)$ & $22.00(19.00-23.00)$ & 0.705 \\
\hline APACHE II score at extubation & $17.0(15.0-19.0)$ & $18.00(12.00-23.00)$ & 0.864 \\
\hline \multicolumn{4}{|c|}{ Vital sign and arterial blood gas before intubation } \\
\hline Heart rate & $100.00(84.00-124.50)$ & $104.00(88.00-118.00)$ & 0.808 \\
\hline Respiratory rate & $22.00(18.00-26.00)$ & $20.00(18.00-22.00)$ & 0.334 \\
\hline $\mathrm{PaCO}_{2}(\mathrm{mmHg})$ & $44.90(30.50-60.95)$ & $38.60(32.00-101.00)$ & 0.229 \\
\hline $\mathrm{PaO}_{2} / \mathrm{FiO}_{2}(\mathrm{mmHg})$ & $131.97(86.90-256.19)$ & $217.14(78.64-291.90)$ & 0.801 \\
\hline$(\mathrm{A}-\mathrm{a}) \mathrm{DO}_{2}$ & $186.97(48.71-411.96)$ & $163.68(34.10-465.58)$ & 0.893 \\
\hline \multicolumn{4}{|c|}{ Vital sign and arterial blood gas before extubation } \\
\hline Heart rate on ventilation & $82.00(73.50-101.00)$ & $87.00(84.00-97.00)$ & 0.440 \\
\hline Respiratory rate on ventilation & $18.00(16.00-21.00)$ & $18.00(16.00-20.00)$ & 0.263 \\
\hline $\mathrm{PaCO}_{2}$ on ventilation $(\mathrm{mmHg})$ & $34.60(30.50-40.30)$ & $36.30(27.70-45.00)$ & 0.565 \\
\hline $\mathrm{PaO}_{2} / \mathrm{FiO}_{2}$ on ventilation $(\mathrm{mmHg})$ & $286.75(215.62-361.00)$ & $321.00(165.75-400.00)$ & 0.753 \\
\hline$(\mathrm{A}-\mathrm{a}) \mathrm{DO}_{2}$ at spontaneous breathing trial & $143.62(110.02-166.10)$ & $97.07(95.32-135.40)$ & 0.232 \\
\hline
\end{tabular}


Supplementary Table 3. Continued

\begin{tabular}{|c|c|c|c|}
\hline Characteristics & Non-reintubation $(n=69)$ & Delayed reintubation $(n=7)$ & P-value \\
\hline \multicolumn{4}{|l|}{ High risk patient } \\
\hline Age older than 65 years & $53(76.8)$ & $7(100.0)$ & $0.334^{\mathrm{a}}$ \\
\hline Body mass index higher than $30 \mathrm{~kg} / \mathrm{m}^{2}$ & $6(8.7)$ & $1(14.3)$ & $0.506^{\mathrm{a}}$ \\
\hline Ventilator duration more than 7 days & $22(31.9)$ & $5(71.4)$ & $0.090^{\mathrm{a}}$ \\
\hline Charlson comorbidity index of 2 or more & $26(37.7)$ & $4(57.1)$ & $0.424^{\mathrm{a}}$ \\
\hline APACHE II score of more than 12 & $66(95.7)$ & $6(85.7)$ & $0.326^{a}$ \\
\hline Heart failure as a cause of intubation & $3(4.3)$ & 0 & $1.000^{\mathrm{a}}$ \\
\hline Moderate to severe COPD & $15(21.7)$ & 0 & $0.333^{\mathrm{a}}$ \\
\hline Failure with first SBT trial & $40(58.0)$ & $6(85.7)$ & 0.234 \\
\hline \multicolumn{4}{|l|}{ Others } \\
\hline Duration of mechanical ventilation before extubation (hr) & 117.15 (70.71-210.29) & 190.08 (82.83-273.66) & 0.337 \\
\hline Hospital day before extubation trial (day) & $6.00(4.00-10.00)$ & $10.00(9.00-13.00)$ & 0.139 \\
\hline \multicolumn{4}{|l|}{ Respiratory failure } \\
\hline Any type of respiratory failure in 48 hours after extubation & $11(15.9)$ & $4(57.1)$ & $0.025^{\mathrm{a}}$ \\
\hline
\end{tabular}

Values are presented as number (\%) or median (interquartile range).

HFNC: high-flow nasal cannula; APACHE II score: Acute Physiologic and Chronic Health Evaluation; ICU: intensive care unit; PaCO ${ }_{2}$ arterial partial pressure of carbon dioxide; $\mathrm{PaO}_{2} / \mathrm{FiO}_{2}$ : ratio of arterial oxygen partial pressure to fractional inspired oxygen; $(\mathrm{A}-\mathrm{a}) \mathrm{DO}_{2}$ : alveolar-arterial oxygen difference; COPD: chronic obstructive pulmonary disease; SBT: spontaneous breathing trial.

${ }^{a}$ Fisher exact test; ${ }^{b}$ Type of respiratory failure can be classified according to each group, if it satisfies both criteria; ${ }^{~}$ Respiratory failure that was not satisfy each criterion. 